\title{
O papel do professor no desenvolvimento motor da criança de 0 a 24 meses
}

\begin{tabular}{ll}
\hline Deise Borks & $\begin{array}{l}\text { Graduada no Curso de Pedagogia. } \\
\text { Universidade Estadual do Rio Grande do }\end{array}$ \\
& $\begin{array}{l}\text { Sul (UE-RGS). São Luiz Gonzaga, RS, } \\
\text { Brasil }\end{array}$ \\
\hline $\begin{array}{l}\text { Viviane Maciel Machado } \\
\text { Maurente }\end{array}$ & $\begin{array}{l}\text { Professora Adjunta da Universidade } \\
\text { Estadual do Rio Grande do Sul (UERGS). } \\
\text { São Luiz Gonzaga, RS, Brasil }\end{array}$ \\
\hline
\end{tabular}

Recebido em: 23 fev. 2017. Revisado em: 17 maio 2017 Aceito: 11 jun. 2017. DOI: http://dx.doi.org/10.21674/2448-0479.32.372-403

\section{Resumo}

Este artigo representa o resultado de uma pesquisa desenvolvida em uma Escola de Educação Infantil que teve como objetivo compreender qual o papel dos professores de berçário com relação ao desenvolvimento motor de crianças de 0 a 24 meses. Este trabalho buscou analisar especificamente qual a repercussão das práticas e atividades pedagógicas que refletem no desenvolvimento motor da criança, qual o trabalho dos professores com relação ao desenvolvimento motor, compreendendo o desenvolvimento motor infantil na faixa etária de 0 a 24 meses, conhecer a prática pedagógica desenvolvida por elas. Compuseram a amostra cinco professoras da escola Municipal de Educação Infantil no Município de São Luiz Gonza- 
ga/RS. O instrumento utilizado foi questionário com perguntas abertas. Para a análise dos dados foi utilizado o método de análise de conteúdo. Constatou-se, entre outros fatores, que as profissionais: a) tem uma concepção sobre desenvolvimento motor, considerando o ambiente e tarefa fatores importantes; b) acreditam que é necessário a educação do corpo com relação ao outro e ao mundo que os cercam; c) tem o conhecimento da fase do desenvolvimento embasadas em Jean Piaget no estágio sensório-motor; d) as práticas realizadas são de acordo com a faixa etária de cada turma, utilizando recursos pedagógicos para o estímulo motor e cognitivo por meio da ludicidade e)consideram fundamental conhecer a fase que a criança se encontra para assim poderem planejar e organizar suas atividades didáticas.

Palavras-chave: Desenvolvimento motor. Berçário. Professores da Educação Infantil.

\section{Abstract \\ The teacher's role in motor development of children from zero to $\mathbf{2 4}$ months old}

This paper presents the results of a research that took place in a Early Childhood Education School in order to understand the importance of teachers in motor development of zero to 24 month age children. This paper intent to analyze the influence of pedagogical and practices activities in children's motor development, investigating the pedagogics' practice made by five teachers from "Escola Municipal de Educação Infantil no Município de São Luiz Gonzaga/RS”. We used a questionnaire with open question. It was found, among others 
factors, that the professionals: a) have knowledge about motor development, considering the environment and tasks important factors; b) believe that body education is necessary in relation with the world that surround the children; c) have knowledge of the development phase grounded in Jean Piaget in the sensory motor stage; d) The techniques they use are according with the class age, using educational resources for the motor and cognitive stimulation through play fullness; e) consider important to know the stage that the child is thus able to plan and organize learning activities.

Keywords: Motor development. Nursery. Teachers of Childhood Education.

\section{Introdução}

A Educação Infantil vem sendo pouco discutida nos aspectos de desenvolvimento motor da criança, nota-se em conversas entre professores de berçário que a preocupação principal é com a adaptação dos novos integrantes, a afetividade e os processos intelectuais. Porém a ligação entre estes fatores é indispensável e de suma importância, onde um depende do outro no caminhar em direção ao desenvolvimento integral do ser humano.

Com o nascimento de uma criança inicia-se um novo ciclo, tanto na vida do bebê como da família, tudo muda no cotidiano da mãe, do pai e dos avós. A rotina dos pais passa a ser 24 horas entorno do filho, até o momento em que tudo precisa voltar ao normal, a mãe ao trabalho e o bebê de um lugar para ficar, onde existam cuidados, carinho e atenção, sendo seguro para os dois. Desta maneira a Escola de Educação Infantil entra na vida da família, que opta por este meio. 
O desenvolvimento de 0 a 24 meses é uma das fases em que a criança está moldando sua mente, conhecendo o mundo através de experiências vividas. Esta etapa é caracterizada pela coragem e curiosidade, onde os bebes arriscam-se, pois, a curiosidade esta aflorada, os primeiros contatos com os objetos a sua volta, as primeiras sensações, os primeiros movimentos e relações convida-os para a nova aventura, a de viver.

Para a família, e, preferencialmente para as mães, é um momento marcante, além de mágico e repleto de surpresas, sustos e aprendizagem para ambos. A cada dia o bebê encaminha-se ao desenvolvimento, desafiando-se, de maneira a provocar, agir, explorar lugares e objetos. As mães parecem se preocupar mais com a saúde e cuidados, do que com o aprendizado, acabando, sem intenção, em reprimir o bebê, não deixando se expor a novos contatos, porém cabe a elas usar estratégias onde a criança aprenda com saúde, nunca deixando de estar atentas a qualquer imprevisto.

Neste período os bebês geralmente aprendem a caminhar, os primeiros passos descompassados, são marcados e anotados em um papel para nunca mais ser esquecidos, aprendem a se alimentar sozinhos, primeiro com as próprias mãos, em seguida manuseando os talheres, as primeiras palavras surgem em seu vocabulário, ainda em construção, assim como tudo que está aparecendo em seu cotidiano, a descoberta acontece a cada dia que passa, bem como a inteligência e os conhecimentos adquiridos através das experiências vividas.

Diante de tantas mudanças em cada etapa do desenvolvimento infantil, e o incentivo em pesquisar esse tema, a pesquisa de conclusão do Curso de Pedagogia deu origem a este artigo, além da necessidade de refletir e pesquisar sobre o papel dos coadjuvantes na vida da criança. E compreender a maneira que estes estão con- 
tribuindo para um desenvolvimento saudável e promissor, já que grande parte das crianças frequentam escolas de Educação Infantil desde muito cedo.

Essa pesquisa teve o objetivo centrado no trabalho dos professores em relação ao desenvolvimento motor de crianças de 0 a 24 meses. Buscou conhecer a prática pedagógica desenvolvida pelos professores que trabalham com os alunos dessa faixa etária, e identificar a repercussão das práticas e atividades pedagógicas centradas no desenvolvimento motor infantil.

Todas as crianças são capazes e anseiam por saber mais, estão repletas de energia para os novos conhecimentos. Sendo assim, é de extrema importância que os pais e professores sejam capazes de acolhê-los, de ensiná-los, de estimulá-los e sustentar esses indivíduos de inúmeras competências. Investindo na educação de qualidade e com observação atenta para o desenvolvimento infantil, potencializando o seu repertório pessoal e ampliando suas habilidades e conhecimento.

Tendo em vista a importância do tema para as crianças e preferencialmente aos pedagogos, que nos dias atuais se deparam com tantas tecnologias no meio escolar, que direta ou indiretamente, interferem no desenvolvimento infantil, de forma positiva e negativa, busco saber o que realmente as crianças estão fazendo na Escola de Educação Infantil que esteja que esteja relacionado ao desenvolvimento motor, um dos quesitos importante para um crescimento com qualidade e saudável.

Quando fui a campo durante os estágios um obrigatório e o outro remunerado, percebi que a tarefa do professor é difícil, a atenção se divide em dez e o auxílio das atendentes torna-se indispensável. O berçário que é a primeira etapa da Educação Infantil, atendendo crianças de zero a vinte e quatro meses, os bebês estão 
aprendendo a caminhar, a falar, são extremamente curiosos e tudo para eles é um desafio, cada um é diferente do outro, são únicos, cada criança se constrói conforme a cultura da família e das pessoas que as cercam. Os professores deveriam propor práticas pedagógicas desde o berçário, não deixando de lado nenhum dos aspectos relacionados ao desenvolvimento da criança. Para isto, além de exigir preparo, conhecimento, comprometimento e dedicação o professor precisa ser um bom observador e compreender as diferentes linguagens da criança.

No decorrer da leitura veremos o contexto das Escolas de Educação Infantil no Brasil e a luta das famílias pela necessidade de abertura de "creches", primeiro termo referido as Escola de Educação Infantil, seguidamente a compreensão de Desenvolvimento Motor e os principais fatores que influenciam no processo de desenvolvimento humano, embasados em um dos principais estudiosos desenvolvimentistas David Gallahue.

Para melhor compreensão apresentam-se as fases abordadas de acordo com a idade, divididas em fase motora reflexiva e fase motora rudimentar, seguido das experiências motoras e os aspectos importantes para o trabalho dos professores em relação ao Desenvolvimento da criança de 0 a 24 meses.

\section{Considerações acerca do desenvolvimento motor}


Os olhares voltados para a criança pequena alicerçada em estudos de vários autores vem de poucos anos atrás, durante muito tempo a criança era vista como um míni adulto, sem os devidos cuidados e atenção, que sabemos, hoje, que são extremamente necessários para um desenvolvimento adequado e de qualidade. É notória a diferença da Educação direcionada aos bebês e crianças com menos de seis anos, em relação a outras épocas, bem como as pesquisas e estudos em torno deste grandioso "universo infantil".

A palavra desenvolvimento vem de desenvolver algo, ou alguma coisa que com o passar do tempo passa por diversas mudanças ou mutações. Segundo Gallahuee Ozmun (2001), durante muitos anos os estudos sobre o desenvolvimento motor eram bastante amplos, o aprofundamento, em sua maioria, relacionadas as áreas cognitivas e afetivas da criança. No entanto através de hipóteses e posteriormente os resultados nos proporcionaram saber que tudo 0 que diz respeito ao desenvolvimento estão fortemente entrelaçados e dependem um do outro para ser adequado, sadio e promissor.

Conforme Gallahue, Ozmun e Goodway (2013), o ser humano desde a concepção, está em constante desenvolvimento, desde o útero até seu nascimento, e por todos os anos de sua vida seu desenvolvimento é muito significativo, onde os aspectos físico, afetivos e cerebral nos primeiros meses de concepção e nascimento são primordiais.

Quando o autor se refere ao desenvolvimento fala de forma geral, em todos os aspectos que envolvem o comportamento do ser humano. As etapas do desenvolvimento vêm atreladas uma na outra, cada etapa é única e os aprendizados trazem consigo as experiências, as diferentes vivências e todos os aprendizados que o sujeito teve durante a vida. O ser humano está em desenvolvimento du- 
rante toda a vida, até mesmo na velhice, embora regredindo em seus movimentos e habilidades físicas e motoras.

Nesse entendimento, o "desenvolvimento motor é a contínua alteração no comportamento ao longo do ciclo da vida, realizado pela interação entre as necessidades da tarefa, a biologia do indivíduo e as condições do ambiente" (GALLAHUE; OZMUN, 2001, p.3). Diversos fatores influenciam no decorrer do processo de desenvolvimento motor, consideramos os principais deles como a genética, as deficiências, as doenças, o meio que está inserido, os estímulos que recebe e experiências que vive.

Para o autor, os fatores ambientais que tem maior influência no desenvolvimento motor são os que o meio fornece, e, por conseguinte, o auxílio de outra pessoa, também, pode proporcionar estímulos, a privação de ambientes e lugares, o temperamento e os vínculos. Os vínculos afetivos são a ligação entre mãe e filho, onde o emocional entra em cena tão forte e importante que dura por toda a vida, ocorrendo durante os primeiros dias de vida.

De acordo com Gallahue e Ozmun (2001) outro fator considerado é o da tarefa física que são a prematuridade, a desordem alimentar, aptidão física que afetam pelo resto da vida do indivíduo. A classe social, o sexo, a cultura também tem grande influência no desenvolvimento e no crescimento motor. Durante muitos anos a criação dos bebês era totalmente restrita, os pais levavam dias ou até meses para sair de casa com eles, quando saiam independente do clima, eram enrolados com cobertas para proteger do frio, assim demorando mais para se movimentarem. Acredito que nos dias atuais isto mudou significativamente, por isto as crianças têm se desenvolvido mais rápido que as de antigamente, sabemos que com o avanço na área médica as mães ficam mais seguras com relação à saúde de seus filhos. 
Tanto a maturação quanto o aprendizado desempenham papéis importantes na aquisição de habilidade motoras. Embora a experiência pareça ter pouca influência sobre a sequência de seu aparecimento, ela realmente afeta a época de aparecimento de certos movimentos e a extensão do seu desenvolvimento. Uma das maiores necessidades das crianças é praticar habilidades em certa época, quando estão aptas, conforme a ciência desenvolvimentista, a beneficiar-se do máximo dessas habilidades. A prática especial antes da aptidão maturacional é de benefício duvidoso. A chave é ser capaz de julgar acuradamente a época na qual cada indivíduo está "maduro" para o aprendizado e, então, fornece uma série de experiências motoras experimentais e efetivas. (GALLAHUE; OZMUN, 2001, p.73).

Conforme Gallahue e Ozmun (2001) diversas pesquisas comprovam que a maturidade e a cultura também são determinantes nas experiências motoras, bem como as condições ambientais podem romper os níveis e a sequência destas habilidades, nesse caso é necessário saber que a sequência das habilidades motoras é previsível, mas o ritmo varia de criança para criança.

Os pais têm o costume de compararem o desenvolvimento dos filhos, "enquanto o fulano já caminha com 9 meses o ciclano foi caminhar com 1 ano e meio, porém a fala está mais desenvolvida". Este discurso não é estranho nos nossos dias, no entanto devemos lembrar que cada ser é único e tem o seu tempo de aprendizagem assim estando apto e preparado para se desenvolver, apesar do desenvolvimento estar relacionado a idade, este não depende desta e sim de outros meios. Por isto não cabe comparação entre crianças, não deve ser levada em consideração pelos pais, professores e pesquisadores.

[...] embora o 'relógio biológico' seja bastante específico quando se trata da sequência de aquisição de habilidades motoras, o nível e a extensão do desenvolvimento são determinados individual e dramaticamente pelas exigências das tarefas em si. (GAL-LAHUE; OZMUN, 2001, p.7). 
Gallahue e Ozmun (2001) denominam a primeira fase da vida como a primeira infância que abrange a idade do nascimento até os 24 meses. O aprendizado acontece quando o ser humano vive uma experiência nova através de experimentação, diferente do desenvolvimento que acontece independente. De acordo com o mesmo autor as habilidades motoras são o processo comum para controle do movimento do corpo e abrangem três categorias de movimento: locomotivas, manipulativas e estabilizadoras.

A criança desta idade se relaciona com os outros por meio da linguagem corporal, utilizando o corpo como primeiro meio de comunicação, através de gestos e movimentos, também por meio do choro, nos mostra que algo não está indo bem e não está satisfeita, ao gesticular pode mostrar o que deseja. Com o corpo a criança nos diz muita coisa, por isto investir em atividades psicomotoras é de grande valia, pois a criança se envolve e se interessa.

Gallahue, Ozmun e Goodway (2013) mostra como podemos conceituar o desenvolvimento motor através de uma ampulheta heurística, nela estão definidos todas as fases e estágios sobre o desenvolvimento motor. Seguindo a linha de que o processo de desenvolvimento motor está basicamente relacionado a alterações no comportamento motor no decorrer da vida a ampulheta serve como base para classificar em que fase ou estágio o indivíduo se encontra, levando em conta todos os fatores que interfere no processo deste desenvolvimento. Dentro das fases e estágios que aparecem nesta vou me deter na fase motora reflexiva e na fase motora rudimentar, no qual envolvem crianças com idade entre zero aos dois anos.

\section{O desenvolvimento motor de crianças de 0 a 24 meses}


Na fase motora reflexiva de acordo com Gallahue e Ozmun (2001) os movimentos reflexivos têm seu início a partir dos movimentos que o feto apresenta dentro do ventre materno, sendo primeira forma de movimento humano, pois já é capaz de sentir, ouvir e principalmente ter o conhecimento sobre o ambiente, provocando assim a atividade motora involuntária. Esta fase se divide em reflexos primitivos e posturais, sendo as bases para 0 futuro do desenvolvimento motor.

Conforme Gallahue e Ozmun (2001) os reflexos primitivos são os movi-mentos que os bebês trazem consigo desde o nascimento, considerados como do instinto de sobrevivência humana, onde através deles tende para a procura de alimento, proteção e segurança. Com a chegada do bebê muitas pessoas que não entendem sobre desenvolvimento, confundem estes reflexos com o conhecido "quebrante". Porém são reflexos primitivos como: reflexo de moro, reflexos de busca e sucção, reflexos buco manuais, reflexo palmar de preensão, reflexo de preensão plantar e de Babinski, reflexos tônicos assimétricos e simétricos do pescoço.

Já os reflexos posturais são semelhantes e vem atrelado com os movi-mentos posteriores voluntários, fornecendo manutenção para posição ereta com relação ao ambiente. Entre os reflexos posturais estão reflexos corretivos labirínticos e visuais, reflexo de levantamento, reflexos de amortecimento e de apoio, reflexos corretivos do pescoço e do corpo, reflexo de engatinhar, reflexo primário de caminhar, reflexo de natação. A fase motora reflexiva pode ser dividida em dois estágios sobrepostos, o estágio de codificação de informações e estágio de decodificação de informações.

A fase que vem seguidamente estudada por Gallahue e Ozmun (2001) é a fase motora rudimentar, esta que abrange desde Rev. Elet. Cient. UERGS, v. 3, n. 2, p. 372-403, 2017 
o nascimento até aproxi-madamente dois anos de idade, outras necessidades aparecem. Neste perío-do a criança tem maior controle e domínio pelos movimentos corporais e são a primeira forma de movimentos voluntários, que ela faz por querer, por desejar e já está apta para tal tarefa. Desde que a criança nasce, entra em uma constante luta pela sobrevivência, a gravidade é uma grande inimiga do ser humano recém-nascido. Tudo que ela vive neste primeiro momento de vivên-cias tende a desenvolver capacidades como estabilidade (controle da cabeça, do pescoço e tronco, sentar-se, ficar em pé), locomoção (arrastar-se, engatinhar, postura ereta) e manipulação (alcançar, segurar, soltar).

De acordo com Gallahue e Ozmun (2001, p.195):

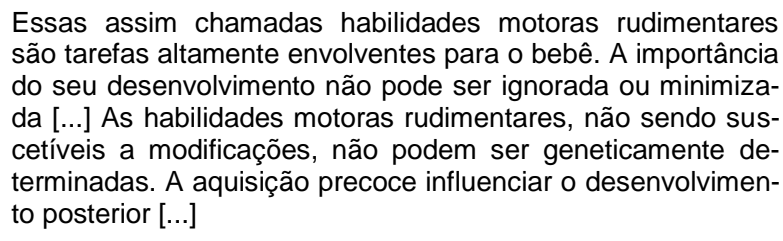

Segundo Gallahue e Ozmun (2001) os movimentos rudimentares também são necessários para a sobrevivência, entre estes movimentos estão: locomotor, manipulação e estabilizador. Os movimentos locomotores referem-se a um movimento de mudança do corpo em relação a um ponto fixo é fundamental para que o indivíduo possa se locomover no ambiente, cabem aqui os movimentos como andar, saltar e correr. O movimento de manipulação envolve um objeto e se caracteriza pela aplicação de força nos mesmos, cabem aqui movimentos como arremessar, receber, chutar, alcançar, agarrar, soltar e outros que envolvam a manipulação de algum objeto. E o movimento estabilizador refere-se ao equilíbrio em relação à força da gravidade movimentos axiais, posturas invertidas e 
rolamentos. Esta fase divide-se em dois estágios, o estágio de inibição de reflexos e estágio de pré-controle.

\section{O professor e as experiências motoras no desenvolvimento da criança de 0 a 24 meses}

Quando se conhece as concepções sobre desenvolvimento motor entende-se que é parte fundamental do desenvolvimento, pois refere-se ao ser humano de forma integral, em todas as fases da sua vida. Faz-se necessário então enxergar a educação de um modo mais abrangente.

Segundo o RCNEI, volume III (BRASIL, 1998, p.18), sobre a atividade psicomotora na Educação Infantil:

Pode-se dizer que no início do desenvolvimento predomina a
dimensão subjetiva da motricidade, que encontra sua eficácia
e sentido principalmente na interação com o meio social, junto
às pessoas com quem a criança interage diretamente. É so-
mente aos poucos que se desenvolve a dimensão objetiva do
movimento, que corresponde às competências instrumentais
para agir sobre o espaço e meio físico.

Nesta perspectiva é preciso compreender quem é a criança e como auxiliar no seu desenvolvimento. Para Wallon (1981) o desenvolvimento do sujeito se dá de maneira integrada ao meio em que se encontra, com os seus aspectos afetivo, cognitivo e motor também integrado, sua idéia de que movimento, pensamento e afetividade estão ligados, e dependem do bom desenvolvimento em conjunto, não podemos então separa-los e sim estudar o homem por meio do seu corpo em movimento. Deste modo, evidencia-se a integração entre o organismo e meio e entre as dimensões: cognitiva, afetiva, e motora na constituição do indivíduo. A primeira função da ação mo- 
tora está ligada à expressão, permitindo que desejos, estados íntimos e necessidades se manifestem.

Segundo Piaget (1987) o desenvolvimento sensório-motor demanda que a criança representa e conquista através da percepção e dos movimentos, todo o universo prático que a cerca. Ele criou condições próprias para uma compreensão mais precisa e real do corpo e suas funções. Esses conhecimentos são de extrema importância na mediação no desenvolvimento das crianças. Através de atividades lúdicas, brincadeiras e jogos podem ampliar os horizontes educacionais.

Através de atividades lúdicas as crianças criam, interpretam e se relacionam com o mundo em que vivem. O profissional da escola de Educação Infantil deve estimular o desenvolvimento psicomotor com o intuito de contribuir para a formação integral da criança. Os estímulos são incentivos que ajudam a criança desde muito pequena a desenvolver-se melhor, e, mais importante que o tipo de estimulo é a maneira com que o estimulo é oferecido, ou seja, com carinho e paciência.

Segundo Gannan (2009) a Escola de Educação Infantil só irá ter cumprido seu objetivo quando compreender que teoria e prática não se separam, portanto, não basta ter somente conhecimento teórico sobre desenvolvimento, mas relacionar estas e a psicomotricidade, sabendo do potencial de cada um, sabendo o que e quando trabalhar as atividades e quando estão aptos para mudar seguir em frente para mais uma experiência.

As Diretrizes Curriculares Nacionais para a Educação Infantil, de (BRA-SIL, 2010, p. 25) indicam que: "[...] as práticas pedagógicas que compõem a proposta curricular da Educação Infantil devem ter como eixos norteadores as interações e a brincadeira", as quais devem ser observadas, registradas e avaliadas. 
$\mathrm{O}$ ato de brincar e jogar reforça a afetividade com quem a criança interage, reforçando os laços, ao brincar principalmente com um adulto que possa participar igualitariamente, torna-se prazeroso para ambos, a criança se sente desafiada e mais interessada pelas atividades. Neste contexto a aprendizagem acontece, trazendo consigo a descoberta e novas vivências, estas atividades lúdicas que são os jogos e brincadeiras devem fazer parte da rotina da criança desde bem pequena, principalmente durante as diferentes infâncias de qualquer ser humano.

A qualidade da brincadeira é resultado da intencionalidade do adulto que coloca sentido nas ações, na organização dos espaços e na escolha dos brinquedos e materiais pedagógicos, na disposição dos móveis. Para isso é necessário observar as crianças para definir as intenções educativas e o papel do professor. O modo como o professor interage com a criança individualmente e em grupo devem facilitar o diálogo estar no mesmo nível que as crianças e junto com elas, mantendo contato direto pelo olhar e pela conversa envolvente é muito importante.

De acordo com Souza (2008), as crianças com dois anos caminham em direção da independência de movimentos, utilizando materiais mais estruturadas para praticar as atividades físicas e de manipulação. O ambiente deve estar preparado para que a criança exerça autonomia ao brincar e oportunidade de aprender a se organizar. Elas estão aprendendo a brincar juntas. Podem-se criar atividades para oferecer desafios motores com criação de circuitos que incluem subir, descer, entrar em túneis, pular obstáculos, utilizando tábuas caixotes e mesas.

Quanto a escolha de brincadeiras, nesta faixa etária os bebês apresentam especificidades importantes, seus ossos ainda são delicados e frágeis, pois há bebês bem novinhos e que permanecem 
deitados, outros sentam, engatinham e andam. É preciso entender e conhecer a criança, com relação ao que já é capaz de fazer e quando está apta para uma próxima atividade, podendo assim progredir, pois cada uma dessas fases é única faz-se necessário planejar ambientes, brinquedos e brincadeiras que ampliem suas experiências.

No primeiro ano de vida já interagem com as outras crianças e com a professora, movimentando-se em espaços planejados para atender seus interesses e necessidades. Já começando a desenvolver a linguagem oral, sua curiosidade os leva a explorar tudo que os cercam, buracos, caixas, túneis, já começam a empilhar, bater, puxar ou empurrar, colocar e tirar objetos brilhantes, coloridos e coisas que se movimentam e produzem som.

\begin{abstract}
Algumas pessoas parecem considerar uma criança como o barro saindo das mãos de um oleiro. Começam a modelar a criança e sentem-se responsáveis pela obra acabada. Isso é um grande erro. (...). Se você aceitar essa ideia de um bebê em marcha, estará então livre para se interessar bastante pela observação do que acontece no desenvolvimento do bebê, enquanto desfruta o prazer de reagir às suas necessidades (WINNICOTT, 2012, p. 30).
\end{abstract}

Mais do que criar situações para os bebês os professores devem acreditar no potencial de cada um deles, deixando explorar objetos e lugares o tempo que desejarem, sem induzir e instigando 0 poder da criatividade individual. A partir desses olhares é possível apresentar alguns elementos na consolidação do processo ensino aprendizagem na Educação Infantil. A importância da motricidade como estratégia de ensino, bem como na construção da corporeidade permite o desenvolvimento integral do ser humano, pois evidencia o caráter integral de suas ações.

Além dos cuidados necessários com saúde e higiene, dentro da escola toda criança passa a ter contato mais direto principalmen- 
te com seus iguais, mas também com diferentes professores e funcionários, ampliando suas relações, socializando-se e integrando-se com outras crianças e adultos, todos inseridos neste meio passam a fazer parte do cotidiano da criança, com esta partilha, passam a ensinar e também a aprender. Esta é considerada a segunda casa dos bebês, neste espaço constrói conhecimentos, reforça a educação que os pais ensinam, porque existem dentro da instituição regras, limites, deveres e a conviver com as diferenças, além de brincar, pois a ludicidade é o foco principal da Educação Infantil. Este é um momento importante para o desenvolvimento da criança, no entanto a estimulação é fundamental e indispensável.

Conforme Antunes (2004), o pensamento lógico da criança funciona a partir de estímulos, dedicação e interesse de um mediador. A criança não aprenderia se não fosse a estimulação e suas vivências, estudos comprovam que durante os anos 60, uma mente estimulada é também uma mente mais inteligente. Matsuo (1997) acredita que a criança deve todos os dias ser estimulada com atividades diversas, através de repetição para melhor assimilação. A utilização de materiais é essencial podendo explorar e ser promissor para o desenvolvimento, estes materiais devem estimular os diferentes sentidos e movimentos.

De acordo com Barbosa e Horn (2001) as atividades diárias devem ter uma sequência, além de serem pensadas e planejadas conforme a necessidade de cada aluno, a realidade da turma e da instituição. A rotina deve ser construída a partir de um conjunto de atividades, possibilitando a iniciativa, a segurança, a confiança, entre outras competências. Tudo que existe no âmbito escolar influencia na aprendizagem dos alunos, desde a chegada, os banheiros, a organização do ambiente, pois desenvolve potencialidades e propõem novas habilidades, fundamental para construção da autono- 
mia, tendo a criança como autora e construtora de seu conhecimento.

Conforme Souza (2008) um dos objetivos da prática psicomotora é ensinar a criança a se movimentar durante todas as fases da sua vida, e com isso contribuir para sua formação e estruturação do esquema corporal. É através do corpo, que a criança descobre o mundo, conhece diversas situações e sensações, além de expandir suas possibilidades de ação. No desenvolvimento total da criança a estimulação através do movimento é essencial, por isso a psicomotricidade ou a manipulação, o uso e manuseio de objetos para ter todas as habilidades forma, são parte de suas aprendizagens naturais que lhes servirão de base para sua maturidade e estar preparado para escrever, ler e falar corretamente. É importante estimular a criança desde uma idade muito precoce por meio do movimento sem forçar sua natureza, para chegar a sua maturidade.

Nesta fase tão importante do desenvolvimento infantil o professor de escola de educação infantil tem um papel muitíssimo importante, acreditar que sua prática pedagógica é fundamental para a formação integral do indivíduo, planejando suas ações criando um ambiente em que a brincadeira e o jogo cumpram seu papel. A intervenção pedagógica de alta qualidade, planejada, faz a diferença pela sua intencionalidade.

Schultz (2002) apresenta um outro aspecto importante e indispensável de se pensar sobre o papel dos professores da Educação Infantil, ressaltando que a formação dos professores dessa faixa etária pode interferir no desenvolvimento físico e intelectual, bem como futuramente na vida da criança. Nesta perspectiva, sabemos que não somente neste momento da educação, mas em todas as etapas de ensino, se faz necessário o profissional que atua com o ser humano em formação ter o conhecimento do que está fazendo 
de como sua prática está afetando e interferindo na criança, além de estar sempre buscando saber mais, segundo a autora, há uma relação entre a formação do educador e a qualidade de seu trabalho.

A intenção deste capítulo foi olhar de um modo especial para a Educação Infantil, primeira etapa da educação básica, especificamente na Escola de Educação Infantil, que ainda se encontra em processo de construção, necessitando de olhares mais atento quanto à formação do professor e ao conhecimento do seu objeto de trabalho, a criança.

\section{Metodologia}

A pesquisa foi de cunho exploratória e qualitativa, buscou entender como o professor intervêm no desenvolvimento da criança de 0 a 24 meses, através de suas relações diárias, interações e atividades propostas. De acordo com Ludke (1986) a pesquisa qualitativa tem como eixo norteador entender as relações do ser humano, onde o ambiente é a fonte de dados e o pesquisador seu principal instrumento. Os dados coletados tende de ser por meio de descrição, obtidos através do contato direto entre pesquisador e campo de estudo. E de acordo com Gil (2002) classifica-se como exploratória, pesquisas que envolvem levantamento bibliográfico.

O campo de estudo foi uma Escola Municipal de Educação Infantil que atende crianças de até dois anos de idade, considerada uma das mais antigas Escolas de Educação Infantil do município de São Luiz Gonzaga/RS. São 29 anos atendendo crianças da comunidade e conta com 60 crianças matriculadas, fechando o total de cinco turmas de berçário. Funcionando em turno integral das 7:30 horas da manhã até as 17:00 horas da tarde. No que se diz respeito 
à carga horária, as professoras atendem por 4 horas ao dia, enquanto as atendentes passam 8 horas.

É importante deixar claro que as professoras questionadas são formadas, três delas no curso de Pedagogia, uma no curso Normal Superior e outra somente Magistério, todas são concursadas e seu trabalho se difere do trabalho das atendentes educacionais, que atuam a maior parte do tempo com os bebês.

A Escola está inserida no centro da cidade, a estratégia do município é conforme as Leis Federais, e as crianças atendidas são moradoras do bairro onde está inserida a instituição, no entanto uma das principais características das famílias são de pertencer a classe média, a maioria filhos de professores, funcionários públicos e trabaIhadores do comércio local, não enfrentando nenhum risco social. A escolha desta Escola aconteceu por ser uma instituição antiga, além de ser a escola onde a pesquisadora frequentou durante a infância, e, também, pelo fato de que muitas das professoras estão há um bom tempo atuando na Educação Infantil.

O instrumento utilizado foi questionário, que de acordo com Gil (2002), a coleta de dados por meio desses instrumentos com pessoas que tiveram experiências práticas com o problema pesquisado, tornam-se ótimos recursos para se chegar a resultados o mais próximo da realidade vivida. A amostra compreendeu cinco professoras, todas do sexo feminino, atuantes em uma escola de Educação Infantil no Município de São Luiz Gonzaga/RS.

O questionário foi composto de seis perguntas abertas, esta forma de coleta de dados segundo Lakatos (2010) é constituído por uma série ordenada de perguntas, que devem ser respondidas por escrito e sem a presença do entrevistador.

Em decorrência do instrumento manipulado, optou-se pela técnica de análise de conteúdo. Essa técnica é considerada 
como um dos procedimentos clássicos para analisar o material textual, não importando qual a origem desse material. (FLICK, 2009, p. 291).

\section{Resultados e Discussão}

O artigo teve como ponto central verificar o papel dos professores no desenvolvimento motor de crianças de 0 a 24 meses que frequentam a escola de Educação Infantil - Berçário. Como forma de conhecer realmente as propostas pedagógicas dos professores da Educação Infantil, acabando com as possíveis hipóteses de estarem utilizando na maior parte da rotina escolar, por recursos limitados, como a televisão e DVD, não dando a atenção necessária aos movimentos corporais e estimulando as capacidades e habilidades motoras devidamente.

Compreendeu-se através do questionário aplicado com cinco professoras de berçário, com seis perguntas abertas, que as profissionais têm uma concepção formada sobre Desenvolvimento Motor, considerando $\mathrm{o}$ ambiente e tarefa fatores importantes, além de acreditarem que é necessário a educação do corpo e dos movimentos, com relação ao outro, ao objeto e ao mundo que os cercam.

As professoras questionadas têm o conhecimento da fase do desenvolvimento embasadas em Jean Piaget no estágio sensóriomotor e as práticas realizadas são de acordo com a faixa etária de cada turma, utilizando recursos pedagógicos para o estímulo motor e cognitivo por meio da ludicidade e consideram fundamental conhecer a fase que a criança se encontra para assim poderem planejar e organizar suas atividades didáticas.

Para melhor discussão dos dados com o referencial teórico, trarei para a discussão cada pergunta com as suas respostas, já que foram bastante parecidas, com mesmo sentido e outras idênticas.

Rev. Elet. Cient. UERGS, v. 3, n. 2, p. 372-403, 2017 
A primeira pergunta destinada as professoras foi, qual o entendimento por desenvolvimento motor na Educação Infantil? As professoras responderam que:

"O desenvolvimento motor se inicia e as primeiras habilidades e coordenações motoras, onde a criança começa a diferenciar corpo e objeto, ao longo de seu desenvolvimento estabelece relações com o mundo, o outro e tudo ao seu redor, por isto a importância termos cuidados desde o banho, a troca de fraldas, a alimentação, a atenção e brincadeiras, sempre direcionando aos aspectos educativos e pedagógicos. De forma individual e sequencial, utilizando o corpo para expressar suas vontades e emoções, os movimentos vão se aprimorando e aperfeiçoando com o decorrer do tempo, nesta fase é muito importante a interação com o ambiente e os estímulos."

Com o desenvolvimento integral as primeiras habilidades motoras, durante a primeira infância, vão sendo aprimoradas através dos estímulos e práticas diárias, onde a criança compreende que seu corpo e os objetos são diferentes. A cada ato, em relação as professoras e bebês, elas buscam com que aprendam esta diferenciação, dando atenção redobrada aos momentos individuais, principalmente porque o egocentrismo é característica do ser humano nesta fase.

Segundo Gallahue e Ozmun (2001), os fatores ambientais que tem maior influência no desenvolvimento motor são os que o meio fornece e o auxílio de outra pessoa pode proporcionar como estímulos, a privação de ambientes e lugares, o temperamento e os vínculos. Explorar todos os espaços dentro da escola é de grande valia, pois tudo dentro da escola está voltado para o lado pedagógico, desde a entrada na escola a criança já está aprendendo.

$O$ adulto quando interage com os bebes através de brincadeiras, é capaz de desafiar através de estímulos, que são os meios que a criança irá utilizar em busca da aprendizagem e conhecimento, ela 
só aprende quando experimenta, deixar fazer, ser e agir, em busca da autonomia.

Conforme Gallahue e Ozmun (2001) na fase motora rudimentar, outras necessidades aparecem. Neste período a criança tem maior controle e domínio pelos movimentos corporais, trazendo com a maturidade suas vontades e desejos. Desde que a criança nasce, entra em uma constante luta pela sobrevivência, no entanto a tendência é de desenvolver capacidades como estabilidade, locomoção e manipulação.

Para Wallon (1981), a primeira função da ação motora está ligada à expressão, permitindo que desejos, estados íntimos e necessidades se manifestem. Essa função continua presente mesmo com o desenvolvimento das possibilidades instrumentais do ato motor.

A segunda pergunta foi quais os aspectos do Desenvolvimento motor que acreditam ser importante aplicar na Educação Infantil. As professoras responderam:

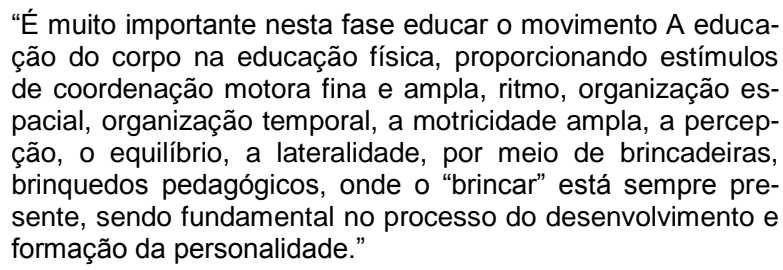

Todas as crianças são capazes e estão cheias de vontade em saber mais, estão repletas de energia para os novos conhecimentos. Os ensinamentos das professoras visando a autonomia e formação da personalidade por meio da educação corporal, com atividades físicas, estimulando os sentidos e movimentos, nesta etapa os bebês geralmente se envolvem nas atividades por curto espaço de 
tempo. No entanto a diversão proporcionada pelas brincadeiras ou o brinquedo utilizado, devem ter um objetivo aliado ao aprendizado, tornando o conhecimento prazeroso.

Sendo assim, é de extrema importância que os pais e professores sejam capazes de acolhê-los, de ensiná-los, de estimulá-los e sustentar esses indivíduos de inúmeras competências. Investindo na educação de qualidade e com observação atenta para o desenvolvimento infantil, potencializando o seu repertório pessoal e ampliando suas habilidades e conhecimento.

Conforme Antunes (2004) o pensamento lógico da criança funciona a partir de estímulos, dedicação e interesse de um mediador. A criança não aprenderia se não fosse a estimulação e as experiências vividas, muitas pesquisas foram feitas durante os anos 60 em que se comprovou que uma mente estimulada é também uma mente mais inteligente.

A terceira pergunta preocupou-se em saber se as professoras identificam em qual fase do desenvolvimento motor as crianças se encontram:

\footnotetext{
"Estão na fase sensório-motor, fase do egocentrismo, onde as crianças começam a diferenciar entre objeto e próprio corpo, e seu pensamento está vinculado ao concreto. Os movimentos são de rolar, engatinhar, sentar sem apoio, agarrar, alguns começam a caminhar, fase linda de descobertas"
}

As professoras têm o entendimento da fase que a criança se encontra nas teorias de Jean Piaget, sem destacar nenhum outro teórico desenvolvimentista. Porém Piaget tem suas pesquisas voltadas principalmente ao desenvolvimento cognitivo, sendo restrito aos aspectos motores infantis.

Segundo Gallahue e Ozmun (2001) é a fase motora rudimentar a criança tem maior controle e domínio pelos movimentos corpo- 
rais e são a primeira forma de movimentos voluntários, que ela faz por querer, por desejar e já está apta para tal tarefa como a estabilidade, locomoção e manipulação.

Segundo Piaget (1987) o desenvolvimento sensório-motor demanda que a criança representa e conquista através da percepção e dos movimentos, todo o universo prático que a cerca. Ele criou condições próprias para uma compreensão mais precisa e real do corpo e suas funções. Esses conhecimentos são de extrema importância na mediação no desenvolvimento das crianças. Através de atividades lúdicas, brincadeiras e jogos podem ampliar os horizontes educacionais.

A quarta pergunta buscou reconhecer que tipo de atividades são realizadas para estimulação motora na turma de atuação:

\begin{abstract}
"Atividades livres e orientadas, utilizamos recursos como motocas, blocos, bola, massas de modelar, tapete sensorial, túnel, brinquedos pedagógicos, fantoches para contar histórias, jogos de diversos tipos, caminhadas com as crianças pela quadra da escola, brincadeiras com movimentos de sentar, levantar, imitar animais, alcançar objetos, circuitos de atividades, músicas e danças."
\end{abstract}

As Diretrizes Curriculares Nacionais para a Educação Infantil, de (BRASIL, 2010, P. 25) indicam que:

"[...] as práticas pedagógicas que compõem a proposta curricular da Educação Infantil devem ter como eixos norteadores as interações e a brincadeira, as quais devem ser observadas, registradas e avaliadas".

$\mathrm{O}$ ato de brincar e jogar reforça a afetividade com quem a criança interage, reforçando os laços, ao brincar principalmente com um adulto que possa participar igualitariamente, torna-se prazeroso para ambos, a criança se sente desafiada e mais interessada pelas atividades. Neste contexto a aprendizagem acontece, trazendo con- 
sigo a descoberta e novas vivências, estas atividades lúdicas que são os jogos e brincadeiras devem fazer parte da rotina da criança desde bem pequena, principalmente dentro durante as diferentes infâncias de qualquer ser humano.

A qualidade da brincadeira é resultado da intencionalidade do adulto que coloca sentido nas ações, na organização dos espaços e na escolha dos brinquedos e materiais pedagógicos, na disposição dos móveis. Para isso é necessário observar as crianças para definir as intenções educativas e o papel do professor. O modo como o professor interage com a criança individualmente e em grupo devem facilitar o diálogo estar no mesmo nível que as crianças e junto com elas, mantendo contato direto pelo olhar e pela conversa envolvente é muito importante.

De acordo com Souza (2008), as crianças com dois anos caminham em direção da independência de movimentos, utilizando materiais mais estruturados para praticar as atividades físicas e de manipulação. O ambiente deve estar preparado para que a criança exerça autonomia ao brincar e oportunidade de aprender a se organizar. Elas estão aprendendo a brincar juntas. Pode-se criar atividades para oferecer desafios motores com criação de circuitos que incluem subir, descer, entrar em túneis, pular obstáculos, utilizando tábuas caixotes e mesas.

Quanto à escolha de brincadeiras, nesta faixa etária os bebês apresentam especificidades importantes, pois há bebês bem novinhos e que permanecem deitados, outros sentam, engatinham e andam. É preciso entender que cada uma dessas fases é única fazse necessário planejar ambientes, brinquedos e brincadeiras que ampliem suas experiências. No primeiro ano de vida já interagem com as outras crianças e com a professora, movimentando-se em espaços planejados para atender seus interesses e necessidades. 
Já começando a desenvolver a linguagem oral, sua curiosidade os leva a explorar tudo que os cercam, buracos, caixas, túneis, já começam a empilhar, bater, puxar ou empurrar, colocar e tirar objetos brilhantes, coloridos e coisas que se movimentam e produzem som.

A quinta e última pergunta aprofundou-se no entendimento das professoras acerca da importância do estímulo e o conhecimento das fases do desenvolvimento motor no planejamento e organização didática de suas aulas:

"Sim, é fundamental, precisamos conhecer as fases do desenvolvimento para poder planejar as atividades, não tendo o perigo de errar, por maior que sejam nossas expectativas, o desenvolvimento deve ser respeitado, pois cada criança tem seu ritmo e o seu tempo."

Cada criança é única, sua cultura e sua bagagem de aprendizados, além de conhecer a teoria de desenvolvimento as professoras tem que conhecer as crianças que ali estão, cada uma com suas individualidades, errar o tipo de atividade é valido, para assim poder focalizar a necessidade de cada aluno, precisando algumas vezes diferenciar as atividades ou adequá-las para o aprendizado acontecer.

Segundo Gannan (2009) a Escola de Educação Infantil só irá ter cumprido seu objetivo quando compreender que teoria e prática não se separam, portanto, não basta ter somente conhecimento teórico sobre desenvolvimento, mas relacionar estas e a psicomotricidade, sabendo do potencial de cada um, sabendo o que e quando trabalhar as atividades e quando estão aptos para mudar seguir em frente para mais uma experiência.

De acordo com Barbosa e Horn (2001) as atividades diárias devem ter uma sequência, além de serem pensadas e planejadas conforme a necessidade de cada aluno, a realidade da turma e da 
instituição. A rotina deve ser construída a partir de um conjunto de atividades, possibilitando a iniciativa, a segurança, a confiança, entre outras competências. Tudo que existe no âmbito escolar influencia na aprendizagem dos alunos, desde a chegada, os banheiros, a organização do ambiente, pois desenvolve potencialidades e propõem novas habilidades, fundamental para construção da autonomia, tendo a criança como autora e construtora de seu conhecimento.

Schultz (2002) apresenta um outro aspecto importante e indispensável de se pensar sobre o papel dos professores da Educação Infantil, ressaltando que a formação dos professores dessa faixa etária pode interferir no desenvolvimento físico e intelectual, bem como futuramente na vida da criança. Nesta perspectiva, sabemos que não somente neste momento da educação, mas em todas as etapas de ensino, se faz necessário o profissional que atua com o ser humano em formação ter o conhecimento do que está fazendo de como sua prática está afetando e interferindo na criança, além de estar sempre buscando saber mais, segundo a autora, há uma relação entre a formação do educador e a qualidade de seu trabalho.

Entendendo que para haver um desenvolvimento integral da criança não se dissocia os aspectos do movimento, afeto e cognição. Acreditando que há um modo específico de trabalhar, que usa muito da interação e da brincadeira. A criança entra na Escola de Educação Infantil, cresce e vai embora, porém suas vivências e experiências dentro da instituição são de extrema significância na vida de cada um, a infância é passageira, mas as cicatrizes deixadas por ela são eternas. Se não for garantido uma educação de qualidade nesse curto e rico espaço de tempo, a educação infantil não terá cumprido seu papel ético, social e educacional. 
Gráficos e tabelas devem ser inseridas no texto à medida que são citados e numerados sequencialmente por algarismos arábicos. O título deve ser colocado acima da tabela e abaixo da figura, devendo ser curto, porém representativo, com descrição completa da informação contida na tabela. As imagens devem ser inseridas no texto com resolução mínima de 300 dpis.

\section{Considerações finais}

A intenção do artigo foi de compreender o trabalho do professor com relação ao desenvolvimento motor da criança que se encontra na primeira infância, com intuito de deixar aberta para novas pesquisas aos que se interessam por conhecer e estudar uma fase da vida que é caracterizada pelo rápido crescimento físico, além de tudo a sua volta chamar atenção, onde a curiosidade e o querer por novas descobertas e experiências estarem entre os principais aspectos nesta etapa.

No andamento deste estudo consegui compreender como acontece o processo de desenvolvimento motor infantil na faixa etária de 0 a 24 meses, bem como os fatores que influenciam para 0 desenvolvimento normal da criança. Nesta perspectiva é possível afirmar que o professor deve se preocupar com tudo relacionado ao desenvolvimento infantil, e principalmente ter o conhecimento necessário, pois há em sua sala de aula vidas se iniciando, trazer atividade que estimulem os diferentes aspectos do desenvolvimento cognitivo, emocional e físico, colocando para dentro do ambiente educacional diferentes recursos pedagógicos, mantendo a criatividade da identidade de professor, confeccionando materiais 
que possam ser utilizados com o objetivo de aprimorar as habilidades e capacidades de cada aluno de sua turma, reconhecendo os limites individuais e o tempo de aprendizado.

É importante ressaltar como a Escola de Educação Infantil é responsável pela maior parte da rotina diária da criança pequena, precisa ter seus espaços, horários, atividades livres e pedagógicas além de profissionais com requisitos básicos e necessários para promover e garantir um desenvolvimento que seja saudável e seguro.

Durante a primeira infância, fase tão importante do desenvolvimento in-fantil o professor de Educação Infantil tem um papel muitíssimo importante, acreditar que sua prática pedagógica é fundamental para a formação integral do indivíduo, planejando suas ações criando um ambiente promissor, onde suas atividades e planejamentos cumpram seu papel. A intervenção pedagó-gica de alta qualidade, planejada, faz a diferença pela sua intencionalidade.

A criança que chega hoje na escola de educação infantil é uma criança que traz todo um saber construído no âmbito familiar, cultural e social, mas também ansiosa por novos conhecimentos, cheia de curiosidade e necessi-tando socializar-se com os iguais. Neste sentido devemos valorizar seus sa-beres, bem como construir outros aprendizados. As crianças pequenas têm necessidade de atenção, cuidados, carinho, segurança, sem os quais dificil-mente sobreviveriam.

Um ambiente estimulante e desafiador conta muito para o aprendizado, pois ao brincar a criança tem capacidade de aprender. O eixo norteador da Educação Infantil é a ludicidade, por isto a brincadeira não pode nunca ser deixada de lado. A idéia de que para aprender tem um horário e a brincadeira tem outro, ficou no passado. Hoje sabemos que é muito mais divertido e prazeroso 
aprender brincando, a partir de jogos pedagógicos, materiais didáticos, brinquedos adequados podemos suprir a necessidade de transmitir o conhecimento e brincar ao mesmo tempo, desenvolvendo as habilidades e capacidades das crianças.

\section{Referências}

ANTUNES, C. Educação infantil: prioridade imprescindível. Petrópolis, RJ: Vozes, 2004.

BARBOSA, M. C. S.; HORN, M. da G. S. Organização do Espaço e do Tempo na Escola Infantil. In.: CRAIDY, Maria; KAERCHER, Gládis Elise P. da Silva. Educação infantil: pra que te quero?. Porto Alegre: Artmed, 2001.

BRASIL. Referencial Curricular Nacional Para a Educação Infantil. Brasília: MEC/SEF, 1998. V.3.

BRASIL. Diretrizes curriculares nacionais para a educação infantil: Secretaria de Educação Básica. Brasília: MEC, SEB, 2010. Disponível em:

<http://ndi.ufsc.br/files/2012/02/Diretrizes-Curriculares-para-a-E-I.pdf>. Acesso em: 05 nov. 20016.

FLICK, U. Métodos de Pesquisa: Introdução a Pesquisa Qualitativa. 3. ed. Porto Alegre: Artmed, 2009.

GANNAN, S. de S. A. Percepção de pais e professores no desenvolvimento de crianças de seis anos comparada com o Teste de Denwer II. Dissertação, Programa de pós-graduação da Faculdade de Medicina, São Paulo, 2009.

\section{GALLAHUE, D. I.; OZMUN, J. C. Compreendendo o Desenvolvimento Motor:} bebês, crianças, adolescentes e adultos. São Paulo: Phorte, 2001.

GALLAHUE, D. L.; OZMUN, J. C.; GOODWAY, J. D. Compreendendo o desenvolvimento motor: bebês, crianças, adolescentes e adultos. Porto Alegre: Artmed, 2013.

GIL, A. C. Métodos e Técnicas de pesquisa social. 4. ed. São Paulo: Atlas, 2002.

IMPORTÂNCIA da psicomotricidade para crianças de 0 a 3 anos. Disponível em: $<$ http://www.efdeportes.com/efd166/a-importancia-da-psicomotricidadeparacriancas.htm $>$. Acesso em: 05 out. 2016. 
LAKATOS, E. M.; MARCONI, M. de A. Fundamentos de metodologia cientifica. 5. ed. São Paulo: Atlas, 2010.

LUDKE, M.; ANDRÉ, M. E.D.A. Pesquisa em educação: abordagens qualitativas. São Paulo: E.P.U, 1986.

MATSUO, T.H. Desenvolvimento Infantil: Insuficiência de Coordenação. Disponível em: <http://tatipilates.wordpress.com/2008/03/05/desenvolvimentoinfantilinsuficienciadecoordenacao/>. Acesso em: 01 nov. 2015.

PATICIA. Os jogos e brincadeiras como ferramentas de estimulação de aprendizagem na educação infantil. Disponível em:

<http://www.posgraduacaoredentor.com.br/hide/path_img/conteudo_542472dea29d7. pdf> . Acesso em: 23 out. 2015.

PIAGET, J. O Nascimento da Inteligência na Criança. Rio de Janeiro: LTC, 1987.

PIAGET, J. A formação do simbolismo da criança. Rio de Janeiro: Zahar, 1975.

SCHULTZ, L. M. J. A criança em situação de berçário e a formação do professor para a educação infantil. Tese de Doutorado. Universidade Estadual Paulista, 2002.

SOUZA, N. N. de. Concepções de educadoras de creche sobre o desenvolvimento da criança na faixa etária de zero a três anos. Dissertação apresentada ao Curso de Pós-Graduação em Educação. Curitiba, 2008.

WALLON, H. As origens do caráter na criança. São Paulo: Nova Alexandria, 1995. . Psicologia e educação da infância. Lisboa: Estampa, 1981.

WINNICOTT, D. W. A criança e seu mundo. 6. ed. Rio de Janeiro: LTC, 2012. 